\title{
ORALIZACIÓN Y POLIFONÍA EN LA LENGUA DEL TURISMO 2.0: EL CASO DE LAS PLATAFORMAS DE RESERVA HOTELERA
}

ORALIZATION AND POLYPHONY IN THE LANGUAGE OF TOURISM 2.0: THE CASE OF HOTEL RESERVATION PLATFORMS

\author{
Maria Vittoria Calvi \\ Università degli Studi di Milano
}

Resumen

Tras unas breves reflexiones sobre los conceptos de oralización y de coloquialización (Briz 2013), este estudio se plantea enfocar algunas de las principales modalidades de oralización que caracterizan al discurso actual del turismo, y esbozar los rasgos de un género emergente, la plataforma de reserva hotelera (Booking, Atrápalo, Trivago, etc.), caracterizada por la inserción sistemática de los comentarios de los turistas en el discurso profesional. En el marco de la teoría de la argumentación (Anscombre y Ducrot, 1983; Fuentes Rodríguez y Alcaide Lara, 2002; Maingueneau, 2012) y de la teoría de la valoración (Kaplan, 2004; Martin y White, 2005; Thompson y Alba-Juez, 2014), el análisis se centrará en algunos fenómenos discursivos, con especial atención por la polifonía y la actitud. En particular, se verá cómo la construcción discursiva de la figura del locutor se asienta en la integración estratégica entre la voz del experto y las voces de otros enunciadores que evalúan a partir de su experiencia personal.

PALABRAS CLAVE: lengua del turismo; oralización; multivocidad; polifonía; plataforma de reserva hotelerta
Abstract

After some brief reflections on the concepts of oralisation and colloquialisation (Briz 2013), this study aims to focus on some of the main modalities of oralisation that characterise the current discourse on tourism, and to outline the features of an emerging genre, the hotel reservation platform (Booking, Atrápalo, Trivago, etc.), characterised by the systematic insertion of tourist comments into professional discourse. Within the framework of the theory of argumentation (Anscombre and Ducrot 1983; Fuentes Rodríguez and Alcaide Lara, 2002; Maingueneau, 2012) and the appraisal theory (Kaplan 2004; Martin and White, 2005; Thompson and Alba-Juez 2014), the analysis will focus on some discursive phenomena, with special attention to polyphony and attitude. In particular, it will be seen how the discursive construction of the figure of the locutor is based on the strategic integration between the voice of the expert with the voices of other enunciators who evaluate from their personal experience.

Key words: language of tourism; oralisation; multivocity; polyphony; hotel reservation platform. 


\section{INTRODUCCIÓN}

El estudio de los fenómenos propios de la lengua hablada ha generado múltiples reflexiones en torno a una nutrida serie de términos contiguos, que se basan en la distinción entre el medio o canal (fónico o gráfico) mediante el que se realiza la comunicación, tales como oral/escrito, oralidad/escrituridad, oralización/escrituralización, etc. (Bustos Tovar, 1995; Blanche-Benveniste, 1998; López Serena, 2007, entre otros). Esta constelación terminológica se combina con otra serie de términos relativos a los estilos o registros en los que se expresa la variación lingüística, de acuerdo con la relación entre los interlocutores y con los diferentes rasgos situacionales y sociales -como, por ejemplo, informal/ vulgar/familiar/formal/solemne, etc. ${ }^{-1}$, que se disponen en un contínuum de mayor o menor formalidad.

También el término coloquial suele referirse al registro del habla que es propio de las relaciones entre iguales en situaciones informales; así lo emplean varios autores, como Vigara Tauste en Morfosintaxis del español coloquial (1992) y Antonio Briz en El español coloquial en la conversación (1998), una obra fundacional que sienta las bases para el estudio de los rasgos pragmalingüísticos del español de registro coloquial en su género prototípico, es decir, la conversación entre familiares, amigos o personas que se encuentran en una situación que induce a la espontaneidad.

Por otra parte, el extraordinario crecimiento de los nuevos medios de comunicación, que tienen en Internet su compendio, ha determinado nuevos y complejos fenómenos de variación e intersección en el contínuum entre oralidad y escrituralidad, entre formalidad e informalidad, entre discursos públicos y privados, etc. Una de las consecuencias más visibles de esta proliferación de modalidades comunicativas es el desarrollo de una nueva forma de escritura, el llamado texto escrito oralizado (Yus, 2017; Mancera Rueda y Pano Alamán, 2013), que comprende, entre otros aspectos, el uso «creativo» de distintos signos gráficos.

Más en general, se observa una tendencia a la oralización o a la coloquialización estratégica (Briz, 2013) propiamente dicha, que atañe tanto a los géneros digitales emergentes como a los tradicionales, empezando por los radiofónicos, los televisivos y los periodísticos (Mancera Rueda, 2009), y que consiste en el empleo sistemático de los rasgos propios del discurso oral de registro coloquial, con una finalidad a menudo persuasiva. Este proceso de oralización comprende también otras vertientes, relativas a la organización discursiva y a la escena de enunciación, tales como la creación de comunidades discursivas basadas en relaciones de proximidad, y la construcción discursiva de la identidad en entornos virtuales (Yus, 2011)2.

\footnotetext{
${ }^{1}$ La bibliografía sobre estas distinciones terminológicas conceptuales es muy amplia; además de las obras que se citan en este apartado pueden verse la síntesis que se encuentra en Mancera Rueda (2009: 28-34) y el panorama de los estudios sobre la oralidad y su temática discursiva que proporciona Cortés Rodríguez (2011).

2 Dentro de los estudios sobre la oralidad, Cortés Rodríguez (2011) señala el aumento de los que se centran en aspectos enunciativos y supraenunciativos (por ej. el enfoque de géneros), frente a los que se detienen en el nivel intraenunciativo $u$ oracional.
} 
Tras unas breves reflexiones sobre el concepto de oralización y otros contiguos, como el de coloquialización (Briz 2013), nos proponemos enfocar algunas de las principales modalidades de oralización que caracterizan al discurso actual del turismo, con especial referencia a la incorporación de la voz del turista como elemento constitutivo de un género profesional emergente, la página de hotel en las plataformas de reservas (Booking, Atrápalo, Trivago, etc.). En el marco teórico del enfoque de géneros discursivos (Shiro, Charaudeau y Granato, 2012), de la teoría de la argumentación (Anscombre y Ducrot, 1983; Fuentes Rodríguez y Alcaide Lara, 2002; Maingueneau, 2012) y de la teoría de la valoración (Kaplan, 2004; Martin y White, 2005; Thompson y Alba-Juez, 2014), el análisis se centrará en algunos fenómenos discursivos, con especial atención por la polifonía y la actitud del locutor. En particular, se hará hincapié en la multivocidad estratégica, viendo cómo la construcción discursiva de la figura del locutor se asienta en la integración estratégica entre la voz del experto con las voces de otros enunciadores que evalúan a partir de su experiencia personal.

\section{ORALIZACIÓN, COLOQUIALIZACIÓN Y POLIFONÍA}

Si bien se mira, el término coloquial contiene en sí la referencia, más que a un registro, a un género discursivo, el coloquio, que se define en el Diccionario de la Lengua Española (Real Academia Española, 2014) como 'Conversación entre dos o más personas', y admite diferentes realizaciones discursivas, tanto literarias ('Género de composición literaria, prosaica o poética, en forma de diálogo') como orales, por lo general planificadas ('Reunión en que se convoca a un número limitado de personas para que debatan un problema, sin que necesariamente haya de recaer acuerdo'). La primera de las tres acepciones, sin embargo, es la que predomina en el sintagma conversación coloquial, que, al reiterar el concepto, subraya el carácter dialógico y responsivo de este género primario de la comunicación oral espontánea, siguiendo las reflexiones fundamentales de Bajtín (1982 [1979]) sobre los géneros del discurso. Para el estudioso ruso, a pesar de estar sometidos a rituales sociales, los géneros primarios constituyen las modalidades enunciativas más directas y auténticas; de ahí que el estudio sistemático de las conversaciones reales haya permitido grandes avances en la descripción de la lengua. Por otra parte, el término coloquialización se refiere al progresivo desplazamiento desde el eje de lo formal a lo coloquial, que se consigue mediante la introducción de diferentes rasgos (como por ejemplo: menor control, mayor proximidad, menor atenuación, menor precisión léxica, etc.) y con diferentes finalidades pragmáticas (Briz, 2013).

Sin embargo, la calidad inmediatamente responsiva de la conversación coloquial no excluye la variación estilística y discursiva; pensemos, por ej., en el empleo de las secuencias narrativas, llamadas también relatos conversacionales o secuencias de historia (Baixauli Fortea, 2000), en las que predomina el carácter referencial, y de los diferentes procedimientos de cita (Reyes, 1994 y 2002), mediante los cuales el locutor (responsable de lo dicho) introduce en su discurso otros enunciadores, como recurso dinamizador y persuasivo (Escribano, 2009), con un efecto de polifonía discursiva (Anscombre y Ducrot, 1994). La polifonía y la interdiscursividad, por supuesto, son frecuentes también en los géneros que Bajtín (1982 [1979]) llama secundarios, es decir, los que son propios de la comunicación cultural, literaria, científica y profesional, y que reelaboran los distintos 
géneros primarios, adaptándolos a sus necesidades: pensemos en el uso literaio del diálogo espontáneo, solo por citar un ejemplo (López Serena, 2007).

En el ámbito de las lenguas de especialidad -es decir, los distintos lenguajes científicos y profesionales-, los géneros discursivos suelen presentar rasgos convencionales más o menos rígidos y estandarizados, que se sitúan en el polo opuesto con respecto a los parámetros de la conversación coloquial: la temática suele ser especializada y el tono formal; predominan la planificación y el discurso monologal; en los géneros que la contemplan (como el debate electoral), la alternancia de turnos está predeterminada. En géneros como la sentencia o el artículo de investigación, se alcanza el grado máximo de convencionalidad.

La irrupción de la comunicación digital, por otra parte, ha propiciado un proceso de oralización que atañe también a las lenguas de especialidad. Como consecuencia de la interactividad y de la ampliación del auditorio, la finalidad interpersonal predomina incluso en géneros especializados como los informes económicos, y se desarrollan nuevos géneros, en los que los usuarios dejan oír su voz también en la relación con los profesionales, tal como ocurre en los foros médicos (Mapelli, 2015) y en los géneros emergentes del campo del turismo.

El término oralización, por su referencia implícita al aspecto fónico, resulta más acorde con el concepto de VOz y con los procedimientos que imprimen una calidad dialógica a textos monologales; lo utilizaré preferentemente, por lo tanto, para referirme a estos fenómenos. Como se verá a continuación, mi objetivo es analizar la incorporación sistemática de distintas voces en textos turísticos monológicos.

\section{LA ORALIZACIÓN EN LENGUA DEL TURISMO 2.0}

Desde el nacimiento de la industria del turismo se ha venido configurando una lengua especializada cuyo género más representativo es la guía de viaje. Entre sus rasgos prototípicos, se destaca la función directiva, en combinaciones variables con la persuasión, que tiene en la evaluación su resorte principal; la impersonalización del discurso y la exclusión de la experiencia personal son algunas de las estrategias en las que se fundamenta, tradicionalmente, la identidad discursiva del experto de los lugares (Baider, Burger y Goutsos, 2004; Santulli, 2007). La preponderancia del discurso evaluativo, sin embargo, hace que la subjetividad se asome incluso en los textos más impersonales.

Por otra parte, no faltan géneros propios del turismo en los que la finalidad interpersonal es dominante. Es el caso de los géneros orales (tales como las interacciones entre operadores y turistas), que presentan un nivel de formalidad generalmente alto, y de los géneros relacionados con la promoción turística (folletos y otros materiales publicitarios), que a menudo optan por una implicación estratégica del interlocutor con evidente finalidad persuasiva, y, por consiguiente, se caracterizan por formas de oralidad fingida (Brumme, 2008). 
En las últimas décadas, el perfil del discurso turístico ha cambiado, debido a una serie de factores de varia índole, tales como la diversificación de los «turismos», el impacto de las estrategias de márketing, el desarrollo del turismo 2.0 y la participación de los usuarios en la comunicación turística (Calvi, 2016a; Edo-Marzá, 2016). En este marco, se impone la necesidad de replantear las clasificaciones tradicionales de los géneros del turismo (Calvi, 2010), teniendo en cuenta tanto los géneros digitales emergentes (blogs, foros de viajeros, reseñas de hoteles, redes sociales, etc.) (Sanmartín Sáez, 2014; Suau-Jiménez, 2016) como las transformaciones de los géneros tradicionales (Calvi, 2016a).

Entre las consecuencias de estos cambios, se destaca la irrupción de la subjetividad en los textos descriptivos y la oralización del discurso. El fenómeno de la oralización, en particular, presenta los siguientes aspectos:

- el refuerzo de la interpersonalidad, es decir, el uso, por parte de los profesionales, del diálogo u otras formas de implicación del interlocutor como recurso persuasivo (Mapelli, 2008; Suau-Jiménez, 2012, 2014 y 2016);

- la irrupción de la voz del turista dentro del circuito comunicativo, que se produce a través de los géneros digitales emergentes (blogs, foros de viajeros, reseñas de hoteles, redes sociales, etc.) (Sanmartín Sáez, 2014; Suau-Jiménez, 2016). Los principales actos discursivos realizados consisten en convertir la experiencia personal en narración y en evaluar los servicios y los lugares visitados;

- la imbricación entre las dos modalidades, es decir, cuando los profesionales incorporan la voz del turista dentro de su propio discurso, con efectos polifónicos. A diferencia de lo que ocurre en los casos de oralidad fingida, en este caso la voz del turista no se configura como simulación sino como voz auténtica y testimonio directo. Volveré más adelante sobre este aspecto, que podemos definir multivocidad estratégica.

En rigor, los géneros reservados a la comunicación «igualitaria» entre los turistas, quedan al margen de la comunicación profesional propiamente dicha. Pero no está de más recordar que dichos espacios interactivos se sitúan en el ámbito de plataformas creadas por profesionales, cuya misión es la de estimular la interacción, funcional a sus propios fines comerciales. Por otro lado, la creciente multivocidad del discurso turístico, que atañe a los diferentes actores, no deja de repercutir en la industria turística. Mariottini y Hernández Toribio (2017) hablan de comunicación epidemiológica para referirse a la fiabilidad que atribuyen los turistas a estos comentarios. No sorprende que el género de la reseña sea uno de los más estudiados, tanto por su impacto en la economía del turismo, como por su caracterización discursiva (Edo Marzá, 2013; Piccioni, 2014; Mariottini y Hernández Toribio, 2017; Suau Jiménez, 2017; Mancera Rueda, 2018). La popularidad de las distintas plataformas (como TripAdvisor) y la inmediatez del medio hacen que muchos usuarios viertan en este género no solo sus evaluaciones de las estructuras reseñadas sino también los testimonios personales de sus viajes. Las reseñas, en definitiva, incorporan tanto breves fragmentos narrativos, como señales de implicación del interlocutor potencial mediante 
consejos, sugerencias y comentarios útiles para orientar el comportamiento de otros turistas.

En cuanto a la inclusión de otras voces, los géneros tradicionales (guías, folletos y reportajes) no excluyen la polifonía y las señales de permeabilidad hacia las "voces cristalizadas del lenguaje" (Reyes, 1994), es decir, los lugares comunes, las creencias y las visiones de la colectividad que el locutor hace propias. En todo caso, la polifonía se realiza sobre todo mediante pero la cita de autoridad; en géneros como los reportajes, por ejemplo, son frecuentes las citas de ilustres escritores-viajeros, que se incorporan en los textos descriptivos tanto para realzar el estilo como en apoyo de las argumentaciones aducidas sobre la unicidad y belleza de los lugares (Canals, 2010). Por su parte, el discurso publicitario reciente suele incorporar al turista en el escenario enunciativo, pero en forma de oralidad fingida, tal como ocurre, por ejemplo, en la conocida campaña de Turespaña Necesito España / I need Spain, que hace hincapié en la experiencia del turista contada por él mismo (Helfrich, 2018).

En algunos géneros emergentes, como veremos a continuación, la inserción de los comentarios de los turistas se convierte en elemento constitutivo del género.

\section{LA MULTIVOCIDAD ESTRATÉGICA EN LAS PLATAFORMAS DE RESERVA HOTELERA}

La pujanza de Internet ha revolucionado tanto el marketing turístico como el sistema de reservas, puesto que el turista tiene acceso directo a diferentes plataformas que permiten organizar un viaje en todas sus etapas y servicios, desde los transportes a la hostelería. Por lo que se refiere, más específicamente, a las reservas hoteleras, sobresalen plataformas como Booking, Expedia, Agoda, Atrápalo, Trivago, Hoteles.com, etc., a las que se puede acceder también desde los sitios web de promoción turística (Martínez-Sala, 2018). TripAdvisor proporciona asimismo un sistema de reservas, pero su función primordial es la de alojar las opiniones de los usuarios, con referencia a destinos, hoteles, restaurantes, agencias y otras organizaciones turísticas.

A pesar de las diferencias, todas las plataformas de reserva hotelera presentan una macroestructura reconocible: en la página principal, que ofrece opciones en varias lenguas, se encuentra el motor de búsqueda de producto; desde la página de resultados, se accede a las fichas de los diferentes hoteles seleccionados; una vez realizada la elección, se puede efectuar el proceso de compra en entorno seguro.

A continuación, nos proponemos individuar los principales rasgos del género, con especial referencia a la página de hotel, y el marco teórico más adecuado para analizarlos. En las secciones dedicadas a los diferentes hoteles, en efecto, se concentra el núcleo de los contenidos de la plataforma. Las observaciones que siguen están basadas en un pequeño corpus piloto de fichas de hoteles de Madrid, recogidas en la web de Booking.com entre noviembre de 2018 y febrero de 201933. La elección de esta plataforma se debe a que es

\footnotetext{
${ }^{3}$ En el periodo indicado, he visitado con regularidad la plataforma y he seleccionado, para el presente artículo, 10 páginas de hoteles de Madrid, de diferente ubicación y categoría, con algunos de los comentarios más recientes [última consulta para todos los ejemplos: 20/02/2019].
} 
la más utilizada ${ }^{4}$, además de ser una de las más representativas en cuanto a la configuración del género que nos ocupa; los demás sitios, en todo caso, siguen el mismo patrón. En particular, todos recogen las opiniones de los clientes sobre los establecimientos visitados: una vez que haya realizado la estancia, el usuario recibe la invitación a evaluar y puntuar las estructuras y los servicios utilizados, poniendo de relieve tanto los aspectos positivos como los negativos.

Este género se caracteriza por la interactividad y la multimodalidad, típicas del medio, y presenta algunas secciones fijas, que comprenden:

- ficha técnica del hotel, en la que se destacan sus rasgos distintivos, también a partir de los comentarios de los turistas;

- informaciones prácticas y fotos del hotel;

- puntuación de los clientes;

- reseñas de los clientes;

- formulario de reserva, con acceso al proceso de compra.

A diferencia de otras plataformas, que se limitan a introducir una sección de opiniones, en Booking se lleva a cabo una gestión más elaborada de las mismas, como se verá también más adelante, con un grado más elevado de integración discursiva. En la descripción realizada por el gestor de la plataforma, por ejemplo, se vuelven a citar los elementos más recurrentes en las opiniones de los clientes.

Desde el punto de vista discursivo, salta a la vista el fenómeno de la polifonía (Anscombre y Ducrot 1994): el locutor, que se asume la responsabilidad de los contenidos del sitio, construye su credibilidad incorporando distintas voces de «testigos presenciales», que cumplen el papel de fuentes legitimadoras. La construcción discursiva de la figura del locutor -en otras palabras, del ethos discursivo (Maingueneau, 2012)- por lo tanto, se basa en la integración entre la voz del experto, que presenta los establecimientos hoteleros siguiendo ciertas pautas convencionales, con las voces de otros enunciadores que lo hacen a partir de su experiencia personal. Téngase en cuenta que, por otra parte, una plataforma de este tipo no se plantea el objetivo de la promoción hotelera en sí, ni de evaluar la calidad, sino de convencer al turista a que realice alguna reserva, no importa dónde.

El dispositivo lingüístico es la cita directa, que convierte en dialógico un discurso monologal (Reyes, 1996 y 2002). El locutor dinamiza el discurso introduciendo las voces de otros enunciadores (Escribano, 2009), a los que confía la tarea de evaluar las instalaciones y los servicios del hotel; la fórmula utilizada para introducir las citas es "Lo que más gustó a los clientes", que remite a la sección del comentario dedicada a destacar lo más apreciado. Esta polifonía se configura como una forma de multivocidad estratégica: la incorporación

\footnotetext{
4 Según las encuestas realizadas por SiteMinder, una empresa que ofrece tecnología para las reservas hoteleras, Booking es la plataforma que genera más ingresos por reserva de habitaciones, tanto en España como a nivel mundial le sigue Expedia, y en tercera posición se sitúan las reservas que se gestionan directamente desde las webs corporativas de los hoteles (https://www. siteminder.com/news/top-12-hotel-booking-revenue-makers-2018/ [consulta: 20/02/2019]).
} 
de otras voces, como veremos, permite dar entrada a varios elementos afectivos, ajenos a la evaluación del experto, pero muy aptos para captar la atención del interlocutor.

Teniendo en cuenta esta dimensión, profundizaremos el análisis del género elegido en el marco de la teoría de la valoración (appraisal), que estudia la construcción discursiva de la actitud y de la postura intersubjetiva (Kaplan, 2004: 58). Esta teoría, además de proporcionar un modelo completo para analizar varios aspectos discursivos, se ajusta a nuestro caso de estudio por la importancia que concede a la negociación de significados con los receptores, que se realiza de forma indirecta mediante la intertextualudad, y dentro de un contexto determinado (Kaplan, 2004; Martin y White, 2005; Alba-Juez y Thompson, 2014).

Recordemos brevemente que la teoría de la valoración abarca tres principales dominios semánticos: la actitud, el compromiso y la gradación. La actitud transmite una evaluación positiva o negativa y se divide en los subsistemas de afecto, juicio y apreciación. El compromiso comprende los recursos que sirven para posicionar la voz del hablante en relación con los enunciados 5 . Se divide en monoglosia (aseveraciones asertivas absolutas) y heteroglosia (existencia de otras voces). Por último, la gradación comprende los valores de fuerza (intensificación) y los de foco (estatus prototípico o marginal del valor representado).

\subsection{La actitud en las plataformas de reservas}

En el género que nos ocupa, el locutor adopta una posición actitudinal aparentemente neutra, fáctica, equilibrada, con limitadas apreciaciones directas; pero elige un claro posicionamiento intertextual, al englobar palabras de otros mediante una expansión dialógica. No adopta posturas evaluativas hacia estos comentarios, pero los incorpora de diferente manera dentro de su propio discurso.

En estos fragmentos, se evidencia la actitud del turista: de esta manera, el locutor integra en el escenario discursivo algunas formas de evaluación que no son propias del profesional, pero que son muy eficaces para establecer una relación empática con el destinatario. En otras palabras, las voces de los turistas se incorporan no solo porque son confiables en calidad de testigo presencialø, sino porque pueden «enganchar» al destinatario.

Sobresale la categoría del afecto que comprende las expresiones relacionadas con las vivencias personales y las secuencias de historia, que remiten a la experiencia y refuerzan la credibilidad. La experiencia es, efecto, una de las categorías emergentes en la lengua del turismo, con especial referencia a las intervenciones directas de los turistas, como se ve también en trabajos como el de Mariottini y Hernández Toribio (2014), que describe los patrones básicos de la narración en un corpus de opiniones en TripAdvisor.

\footnotetext{
${ }^{5}$ Como subraya Kaplan (2004: 67), esta categoría es similar a otras de uso corriente en el análisis del discurso, tales como modalidad epistémica, evidencialidad, mitigación, intensificación y metadiscursividad.

${ }^{6}$ En algunas plataformas como TripAdvisor, también se puede valorar el grado de fiabilidad de los evaluadores, de acuerdo con su «antigüedad» en el oficio, el número de recensiones realizadas, etc.
} 
En muchas opiniones predominan las formas nominales, pero en otras aparecen los tiempos del pasado, que remiten a la estancia real. Cuando aparece la narración, el turista convierte su recuerdo en testimonio ejemplar, que puede resultar útil a otros:

(1) La ubicación es excelente. El trato del personal muy cercano! y la ambientación está muy bien lograda. Llegamos a las 6 am y nuestro check in era a partir de la 14hs y nos dieron la habitación bien temprano igual!!!" (The Pavilions Madrid Hotel) ${ }^{7}$ Sebastian きUruguay

(2) Hay unas habitaciones mucho peores y mas anticuadas que otras. En este caso nos tocó una habitación antigua y más bien pequeñita aunque la cama y la ubicación son excelentes (Hotel Liabeny) Andromacus España

(3) $\mathrm{M}[\mathrm{e}]$ costo contactar con ellos telefonicamente. Cobran el total de la estancia en el momento que realizas la reserva,cuando llegue y lo comenté me dijeron que lo hacían para asegurarse de que las habitaciones no se les quedarán colgadas como muchas veces que las cancelaban a última hora y no se podían alquilar (Hostal Odesa)

Maria ¿España

En (1), la positiva valoración del personal se acompaña con el relato de una experiencia placentera, es decir, la posibilidad de disponer de la habitación antes del horario establecido, a lo mejor tras un largo viaje. En (2) y en (3), las críticas se relacionan con incidencias negativas, que, sin embargo, no menoscaban la valoración global ("aunque la cama y la ubicación son excelentes"), y que pueden servir como advertencia para otros viajeros.

En ejemplos como el siguiente (4), la valoración del hotel parte de una experiencia personal agradable, que queda implícita tanto en el título elegido ("Ideal para desconectar en un viaje de negocios") como en el comentario, aunque el usuario evita las referencias al yo y prefiere las formas impersonales, dando ejemplaridad a lo vivido:

(4) Ideal para desconectar en un viaje de negocios

Hace de tu estancia un espacio íntimo y tranquilo. La habitación muy confortable (Hotel Nuevo Madrid). Miguel España

La categoría del juicio, que se refiere a la evaluación del comportamiento de acuerdo con la estima social, también es propia de las opiniones de los turistas. Es muy frecuente, en particular, la evaluación del comportamiento del personal (atento, amable, etc.) -o de los dueños, en el caso de los establecimientos de gestión directa o familiar- cuyos miembros se perciben como participantes en una interacción y no como meros exponentes de un servicio: de esta manera, el juicio se relaciona también con la experiencia vivida y con la categoría del afecto, como ya se ha visto en el ejemplo (1). La cordialidad, la atención y la disponibilidad se distinguen como valores positivos, esenciales para que la valoración general del establecimiento hotelero sea buena:

(5) El personal siempre dispuesto a ayudar, es muy amable. La ubicación es magnífica (Hotel Santo Domingo) Jose [a]México

(6) Excelente trato por personal del área húmeda, más que amables!

El trato por el personal de la recepción fue basico (Hotel Nuevo Madrid)

${ }^{7}$ En este igual que en todos los ejemplos se mantiene íntegra la versión original, incluidas eventuales erratas e incorrecciones. Solo en algunos casos, se añaden rectificaciones entre corchetes, para facilitar la lectura. 
Juan España

(7) Los dueños muy simpáticos, agradables e interesados en que nuestra estancia fuera de lo más cómoda posible (Hostal Odesa)

Merche España

Como se ve en (6), en la valoración del comportamiento se diferencia entre varias tipologías de personal, estigmatizando la poca atención recibida por parte de los recepcionistas. En (7) es evidente la relación entre el trato de los dueños y la calidad de la estancia.

La apreciación también es una categoría institucionalizada. En el caso de los hoteles, se trata de una evaluación estética y social en función del sistema general de clasificación hotelera y de evaluación experta de las instalaciones, que comprende rasgos estéticos, disponibilidad de servicios, funcionalidad, ubicación, etc. A diferencia del afecto y del juicio que solo se hallan en las opiniones de los turistas, la apreciación atañe también al locutor, aunque desde un diferente posicionamiento. Se trata de un profesional, por lo tanto de un experto, pero su papel de intermediario se traduce, como ya se ha dicho, en una posición actitudinal equilibrada; se limita a indicar la categoría oficial del hotel y a destacar los puntos de fuerza de toda instalación (ubicación, diseño, relación calidad-precio, servicios), tratando siempre de activar respuestas positivas:

(8) ¡Uno de los bestsellers en Madrid! Este hotel elegante se encuentra en el norte de la ciudad, a 10 minutos en coche del centro de convenciones IFEMA y con acceso directo desde la autopista M30. Ofrece centro de fitness y relajación y servicio de traslado gratuito los fines de semana (Hotel Nuevo Madrid).

(9) El Hostal "Odesa" Madrid-Centro ofrece alojamiento económico en pleno centro de Madrid y cuenta con habitaciones amplias decoradas en estilo moderno.

(10) El Hotel Santo Domingo se encuentra en el centro de Madrid, a 150 metros de la Gran Vía y de la estación de metro de Santo Domingo. El establecimiento dispone de terraza en la azotea con piscina y vistas a la ciudad. Las habitaciones ofrecen una decoración individual y cuentan con WiFi gratuita.

En sus opiniones, los turistas también utilizan algunas categorías de la evaluación técnica (calidad, disponibilidad de servicios, etc.), pero suelen dar prioridad al impacto, es decir, la repercusión de los distintos aspectos en la vivencia personal; de ahí que la comodidad y la limpieza sean los rasgos más apreciados, aunque también se insiste en detalles de todo tipo, poniéndolos en relación con emociones y sensaciones, tanto visuales (decoración y panorama) como auditivas (ausencia de ruidos), táctiles (materiales, sobre todo en las camas) e incluso olfativas:

(11) Es un hostal, pero con instalaciones más bien de un hotel, tiene aire acondicionado frío/calor, caja fuerte, mini bar, secador de pelo, tv plana, escritorio, recepción 24hrs, mampara en la ducha... Ubicación genial a dos pasos de metro Antón Martín. Las camas son cómodas, ducha con mucha presión y muy caliente. Mi habitación era interior por lo que no había ruido. En mi opinión un 10 valorando la categoría de hostal (Hostal Atocha Almudena Martín).

Dave-med $\Xi$ España

(12) La habitación era acogedora, la cama muy cómoda y las sábanas realmente suaves. Me gusto la idea de poner libros en la habitación (historia de Madrid, arte, etc..). La decoración me gustó, tanto de la habitación como del restaurante (The Pavilions Madrid Hotel). Pilar España

(13) El hotel entero huele genial, todo muy limpio, cómodo, bañera amplia y vistas muy chulas (Hotel Nuevo Madrid)

Nerea España 
En (11) el usuario evalúa el establecimiento desde la perspectiva del esperto, subrayando que las instalaciones y los servicios son superiores al estándar de los hostales; a continuación, se incide en los aspectos más apreciados y las sensaciones placenteras suscitadas (silencio, comodidad de las camas y de la ducha). Al positivo impacto en la experiencia personal también contribuyen detalles como la decoración, la disponibilidad de libros (12), el buen olor y las vistas (13).

\subsection{El compromiso}

Ante todo, la categoría del compromiso es propia del locutor, que, de acuerdo con lo que ya se ha dicho sobre la apreciación, limita las aseveraciones asertivas monoglósicas a pocos trazos, y elige una postura heteroglósica al dar entrada a otras voces. Esta postura se manifiesta mediante recursos de extravocalización (White, 2003), o expansión dialógica, de dos maneras: dentro de marcos específicos, claramente identificables en la visualización de la página (las secciones reservadas a las voces de los turistas), o dentro del propio discurso, es decir, la ficha descriptiva de la que es responsable directo el locutor.

Como se ha visto, en la página de cada hotel se encuentran tres secciones dedicadas a los comentarios de los turistas: la ventana dinámica que se sobrepone a la imagen, la columna a la izquierda y la de la derecha. Las dos primeras funcionan como un diálogo directo; en la columna a la izquierda, las distintas voces, puestas entre comillas, están introducidas por la fórmula "Lo que más gustó a los clientes:", que se repite en todas las páginas. De esta manera, los distintos enunciadores entran dentro del escenario discursivo como si de una actuación teatral se tratara; cada uno de ellos está identificado mediante los datos que ha elegido utilizar como públicos (generalmente, nombre y nacionalidad), y se asume directamente la responsabilidad de lo dicho. El locutor se limita a reconocer el discurso atribuido, sin distanciarse de estas voces, aunque declara que ha seleccionado la vertiente positiva de los comentarios.

En el marco de la ficha descriptiva también se emplean recursos de extravocalización, aunque se produce una mayor integración discursiva. El locutor abandona rápidamente la postura monoglósica para apoyar sus aseveraciones en las evaluaciones y en los comentarios de los clientes, que introduce mediante fórmulas resumidoras propias del discurso indirecto, tales como "Nuestros clientes dicen", "A las parejas les encanta", que se repiten con regularidad en las diferentes páginas:

(14) Nuestros clientes dicen que esta parte de Madrid es su favorita, según los comentarios independientes. A las parejas les encanta la ubicación - Le han puesto un $\mathbf{9 , 4}$ para viajes de dos personas.

Este alojamiento también tiene muy buena puntuación por la mejor relación calidad-precio en Madrid. Los clientes sacan más partido a su dinero en comparación con otros alojamientos de la misma ciudad (The Pavilions Madrid Hotel).

La alternancia entre distintas voces también le permite al locutor dinamizar su exposición mediante recursos de coloquialización estilística, como el empleo recurrente de la fórmula "es una opción genial", a través de la que se subrayan las ventajas de la ubicación:

(15) Centro de Madrid es una opción genial para los viajeros interesados en comer tapas, la arquitectura y los parques. 
Nuestros clientes dicen que esta parte de Madrid es su favorita, según los comentarios independientes (Hotel Vincci The Mint).

En definitiva, las opiniones de los clientes ofrecen un respaldo al discurso del locutor, que resume los aspectos más valorados para caracterizar cada página de hotel: cada uno de ellos puede ser "una opción genial", dependiendo de las necesidades y las expectativas del cliente. Los comentarios críticos, en cambio, quedan en la sombra del segundo plano, aunque el viajero puede acceder a ellos sin dificultad.

Por su parte, las opiniones suelen ser monoglósicas; el respaldo principal está, como se ha dicho, en la experiencia personal, aunque el empleo de la primera persona del plural implica a otros testigos silenciosos que comparten la misma opinión. Entre los principales recursos utilizados para reforzar el compromiso sobresale la declaración del propósito de volver a alojarse en el mismo establecimiento:

(16) Será nuestro hostal siempre que vengamos (Hostal Odesa) Silvia España

Entre las estrategias de posicionamiento adoptadas por los viajeros, también cabe mencionar la atenuación, que a menudo matiza los comentarios negativos, como se ve, por ejemplo, en el ejemplo (17). Cuando la valoración global es buena, el cliente señala los elementos negativos con reserva, insistiendo en que la crítica no invalida la satisfacción general:

(17) A pesar de las incomodidades citadas, lo pasamos bien. Me gustó la ubicación, el servicio en general, las comidas el bar,

No me gusto la habitación, pequeña. No me gusto, también,tener que coger dos ascensores para llegar a la habitación y tener que caminar un trecho para coger el segundo ascensor (Hotel Santo Domingo). Juan España

En este ejemplo, como se ve, el título del comentario sirve para colocar los datos negativos en el marco de una experiencia satisfactoria, reduciendo el impacto de las incomodidaes.

En esta somera revisión del género, no hemos encontrado críticas expresadas con una elevada carga agresiva, a diferencia de lo que ocurre en plataformas como TripAdvisor, en las que el tono emocional y semántico de las opiniones es a veces muy elevado (SuauJiménez, 2017). Este rasgo no excluye, sin embargo, que se acuda a estrategias de atenuación, vinculadas con la cortesía (Mancera Rueda, 2018).

\subsection{La gradación}

Dentro del sistema de la valoración, la gradación es un espacio semántico de escala, que comprende los recursos utilizados para intensificar o disminuir la fuerza de los enunciados, así como para graduar el foco de las categorizaciones semánticas (Kaplan, 2004: 72). La intensificación es, de por sí, un rasgo propio de la lengua del turismo, cuyo tono «eufórico» (Dann, 1996: 65) alcanza su cota máxima en los géneros destinados a la promoción, y se expresa mediante un uso abundante de la adjetivación, a menudo en combinaciones poliléxicas recurrentes, del tipo «magníficas vistas», «impresionante panorama», «magnífica 
ciudad», «incomparable patrimonio», etc. (Calvi, 2016b). En cuanto a las opiniones de los turistas, también se destaca el uso de las formas evaluativas de grado máximo e hiperbólicas (Edo Marzá, 2013).

En el género que nos ocupa también aparecen, tanto en el discurso del experto como en las intervenciones de los turistas, algunas de las combinatorias típicas («vistas impresionantes», "vistas maravillosas», etc.), pero en el marco del testimonio directo tienen cabida también formas menos convencionales y más cercanas a la conversación espontánea, como se ve en el ejemplo que sigue:

(18) Todo, todo me gusto la ubicación el estilo con que se conserva la atención personalizada del personal y la amabilidad el desayuno la cena la conserjería es de primera la calefacción central y no por aire acondicionado es un gran plus pues llegas a la habitación y está caliente en invierno tanto que da gusto desvestirse, el baño con todas las comodidades el tamaño de las habitaciones. Se come excelente y el metre y demás personas del restaurante son encantadores! Un hotelazo en pleno centro de Madrid a dos pasos de Gran Vía y de Sol en una burbuja de silencio y tranquilidad, ah y además con parkinng! Felicitaciones por mantener el verdadero estilo de un gran hotel !! Ah y con parada de taxi en la esquina (Hotel Labeny)

Silvia きUruguay

En este fragmento confluyen varios de los elementos ya señalados, como la apreciación basada en el impacto y en la experiencia personal ("está caliente en invierno tanto que da gusto desvestirse"), y el juicio positivo sobre el comportamiento del personal ("amabilidad", "encantadores"). Además, se acumulan varios recursos intensificadores, como la repetición ("Todo, todo me gusto") y el uso de adjetivos de valor positivo y grado máximo ("se come excelente"), expresiones metafóricas ("una burbuja de silencio y tranquilidad”) y marcadores aditivos ("ah y además con parkinng!"). También sobresalen algunas formas propias de la lengua hablada de registro coloquial, como "hotelazo", junto con marcas de espontaneidad: véase, en particular, cómo la turista emplea el marcador "ah" para agregar algunas piezas finales a su comentario, recalcando, de esta manera, la planificación "sobre la marcha" de su discurso. Los valores de foco se expresan mediante elementos léxicos que presentan el hotel reseñado como prototípico de su categoría: "el verdadero estilo de un gran hotel".

Sin embargo, el empleo de los recursos propios del texto escrito oralizado es limitado, ni se encuentran iconos y otros ítems gráficos: el turista es consciente de los vínculos del género, y del tipo de relaciones interpersonales que admite, y reserva los perfiles de coloquialización más desenvuelta a los entornos de mayor proximidad. También Piccioni (2014) observa que en la reseña de hotel el recurso a la oralización es limitado, pero, como se ha visto, su colocación en el marco de un género profesional produce una marcada amplificación.

\section{NOTAS FINALES}

La amplia difusión de las plataformas de reserva hotelera dentro del turismo 2.0 justifica el interés de su estudio, aunque la limitada extensión del corpus recogido no permite extraer conclusiones decisivas sobre el fenómeno. El caso de estudio elegido, sin embargo, ofrece elementos suficientes para considerar este género como uno de los más representativos 
de las tendencias actuales de la lengua profesional del turismo, que hace propias las instancias comunicativas de los usuarios.

La aparición de la voz del turista dentro del circuito comunicativo, a través de los géneros digitales emergentes, es uno de los procesos más destacados de la comunicación turística; por su parte, los profesionales integran estas voces dentro de su propio discurso, poniendo a punto unas pautas gráficas y discursivas reconocibles. Dentro de los movimientos retóricos del género, sobresale la plurivocidad estratégica, una instancia enunciativa mediante la cual el locutor configura su credibilidad dando la palabra a varios enunciadores, que asumen el papel de testigos presenciales.

La teoría de la valoración ofrece un marco teórico adecuado para analizar las actitudes del locutor y de los enunciadores que se incluyen en el escenario discursivo, habida cuenta de que la evaluación representa uno de los rasgos más sobresalientes de la lengua del turismo. Asimismo, la incorporación de la voz del turista da entrada a fenómenos de oralización y coloquialización de varios tipos, cercanos a otros géneros emergentes, aunque sometidos a los vínculos propios de un marco genérico de tipo profesional.

\section{REFERENCIAS BIBLIOGRÁFICAS}

Alba-Juez, Laura y Geoff Thompson (2014): «The many faces and phases of evaluation", en Thompson, Geoff y Alba-Juez, Laura (eds.), Evaluation in Context, Amsterdam/Philadelphia, John Benjamins, 323.

Anscombre, Jean-Claude y Oswald Ducrot (1983): L'argumentation dans la langue, Bruxelles, Mardaga.

Baider, Fabienne, Marcel Burger y Dionysis Goutsos (eds.) (2004): La communication touristique. Approche discursive de l'identité et l'altérité, Paris, L'Harmattan.

Baixauli Fortea, Inmaculada (2000): «Las secuencias de historia», en Briz, Antonio y Grupo Val.Es.Co (eds.), ¿Cómo se comenta un texto coloquial?, Barcelona, Ariel, pp. 81-107.

Bajtín, Mijail M. (1982 [1979]): «El problema de los géneros discursivos», en Bajtín, Mijail M., Estética de la creación verbal, Madrid, Siglo XXI, 245-290. Título original: Éstetika slovesnogo tvorchestva.

Blanche-Benveniste, Claire (1998): Estudios lingüísticos sobre la relación entre oralidad y escritura, Barcelona, Gedisa.

Briz, Antonio (1998): El español coloquial en la conversación, Barcelona, Ariel.

Briz, Antonio (2013): «Variación pragmática y coloquialización estratégica. El caso de algunos géneros televisivos", en Fuentes Rodríguez, Catalina (ed.), (Des)cortesía para el espectáculo: estudios de pragmática variacionista, Madrid, Arco/Libros, 89-126.

Brumme, Jenny (ed.) (2008): La oralidad fingida: Descripción y traducción. Teatro, cómic y medios audiovisuales, Madrid/Frankfurt am Main, Iberoamericana/Vervuert.

Bustos Tovar, José Jesús (1995): «De la oralidad a la escritura", en Cortés, Luis (ed.), El español coloquial, Actas del I Simposio sobre análisis del discurso oral, Almería, Universidad de Almería, 11-28.

Calvi, Maria Vittoria (2010): «Los géneros discursivos en la lengua del turismo: una propuesta de clasificación», Ibérica, 19, 9-32.

Calvi, Maria Vittoria (2016a): "Guía de viaje y turismo 2.0: Los borrosos confines de un género", Ibérica, 31, 15-38.

Calvi, Maria Vittoria (2016b): «Léxico de especialidad y lengua del turismo», en Duffé Montalván, Aura Luz (ed.), Estudios sobre el léxico. Puntos y contrapuntos, Bern, Peter Lang, 187-214.

Canals, Jordi (2010): «Describir el viaje», en Canals, Jordi y Elena Liverani (eds.), Viaggiare con la parola, Milano, FrancoAngeli, pp. 49-66.

Cortés Rodríguez, Luis (2011): «La oralidad y su temática discursiva a partir de 2000", en Fant, Lars y Ana María Harvey (eds.), El diálogo oral en el mundo hispanohablante. Estudios teóricos y aplicados, Madrid/Frankfurt am Main, Iberoamericana/Vervuert, 17-34. 
Dann, Graham M. S. (1996): The Language of Tourism. A Sociolinguistic Perspective, Oxon UK, CAB International.

Edo Marzá, Nuria (2013): «The Formation of the Image of Top-Ranked Hotels through Real Online Customer Reviews: A Corpus-Based Study of Evaluative Adjectives as ImageFormers/Providers", International Journal of English Linguistics, 3, núm. 4, 15-35.

Edo Marzá, Nuria (2016): «Communication in tourism 2.0: redefining roles, restating 'the traditional', reaching the world», Ibérica, 31, 914.

Escribano, Asunción (2009): Las voces del texto como recurso persuasivo, Madrid, Arco/Libros.

Fuentes Rodríguez, Catalina y Esperanza R. Alcaide Lara (2007): La argumentación lingüística y sus medios de expresión, Madrid, Arco/Libros.

Helfrich, Uta (2018): «l Need Spain - New Ways of Representing the Tourist Experience», en Held, Gudrun (ed.), Strategies of Adaptation in Tourist Communication, Leiden/Boston, Brill, pp. 73-94.

Kaplan, Nora (2004): «Nuevos desarrollos en el estudio de la evaluación en el lenguaje: la teoría de la valoración», Boletín de Lingüística (Universidad Central de Venezuela), 22, 52-78.

López Serena, Araceli (2007): Oralidad y escrituralidad en la recreación literaria del español, Madrid, Gredos.

Maingueneau, Dominique (2012): Analyser les textes de communication, Paris, Colin, 2.a ed.

Mancera Rueda, Ana (2009): Oralización de la prensa española. La columna periodística, Bern, Peter Lang.

Mancera Rueda, Ana (2018): «La atenuación lingüística en las reseñas digitales de hoteles y restaurantes en español», CLAC. Círculo de Lingüística Aplicada a la Comunicación, 73, 5376.

Mancera Rueda, Ana y Ana Pano Alamán (2013): El español coloquial en las redes sociales, Madrid, Arco/Libros.

Mapelli, Giovanna (2008): «Las marcas de metadiscurso interpersonal de la sección 'turismo' de los sitios web de los ayuntamientos», en Calvi, Maria Vittoria, Giovanna Mapelli y Javier Santos López (eds.), Lingue, culture, economia: comunicazione e pratiche discursive, Milano, FrancoAngeli, 173190.

Mapelli, Giovanna (2015): «La comunicación (e)médico/(e)-paciente en los foros de salud", en Chierichetti, Luisa y Giovanna Mapelli (eds.), Discurso médico. Reflexiones lingüísticas, históricas y lexicográficas, Bergamo, CELSB, 131-150.

Mariottini, Laura y Hernández Toribio, María Isabel (2017): «La narración de experiencias en TripAdvisor», RILCE Revista de Filología Hispánica, vol. 33, núm. 1, 302-30.

Martin, y Peter R.R. White (2005): The Language of Evaluation: Appraisal in English, Basingstoke, Palgrave Macmillan.

Martínez-Sala, Alba-María (2018): «Marketing 2.0 aplicado al sector turístico: la función comercial de los sitios webs de las organizaciones de marketing de destinos", Vivat Academia. Revista de Comunicación, núm. 143, pp. 1-23.

Piccioni, Sara (2014): «Cortesía y lenguas de especialidad entre lo local y lo global: el caso de las reseñas de hoteles en español e inglés», Normas 4, 93-116.

Real Academia Española (2014): Diccionario de la lengua española, 23. a ed., Madrid, Espasa, versión electrónica 23.2. actualizada desde 2018 [consulta: 20/02/2019].

Reyes, Graciela (1994): Los procedimientos de cita: citas encubiertas y ecos, Madrid, Arco/Libros.

Reyes, Graciela (2002): Los procedimientos de cita: estilo directo y estilo indirecto, Madrid, Arco/Libros.

Sanmartín Sáez, Julia (2014): «A propósito de los 'cibergéneros': el portal oficial de turismo de España 'spain.info' y el facebook institucional 'see spain' como objeto de análisis", LEA. Lingüística Española Actual, 36, 5-34.

Santulli, Francesca (2007): «\|l discorso procedurale come tratto distintivo della guida turistica», en Garzone, Giuliana y Salvi, Rita (eds.), Linguistica. Linguaggi specialistici. Didattica delle lingue, Roma, CISU, 227-240.

Shiro, Martha, Patrick Charaudeau y Luisa Granato (eds.) (2012): Los géneros discursivos desde múltiples perspectivas: teorías y análisis, Madrid/Frankfurt am Main, Iberoamericana/Nervuert.

Suau-Jiménez, Francisca (2012): «Páginas web institucionales de promoción turística: el uso metadiscursivo interpersonal en inglés y español», en Sanmartín Sáez, Julia (ed.), Discurso Turístico e Internet, Madrid/Frankfurt am Main, Iberoamericana/Vervuert: 125-154.

Suau-Jiménez, Francisca (2014): «Dialogic voices of writers and readers in traveller forums through interpersonality», en Gil Salom, Luz y Carmen Soler Monreal (eds.), Dialogicity in Written Specialised Genres, Amsterdam, John Benjamins, Dialogue Studies, 137-163. 
Suau-Jiménez, Francisca (2016): «What can the Discursive Construction of Stance and Engagement Voices in Traveler Forums and Tourism Promotional Websites Bring to a Cultural, Cross-generic and Disciplinary View of Interpersonality?», Ibérica, 31, 199-220.

Suau-Jiménez, Francisca (2017): "Construcción discursiva de la subjetividad en lengua inglesa: cuando los viajeros se quejan a través de sus opiniones en TripAdvisor», CLAC. Círculo de Lingüística Aplicada a la Comunicación, 72, 7994.

Thompson, Geoff y Laura Alba-Juez (eds.) (2014):
Evaluation
in
Context,

Amsterdam/Philadelphia, John Benjamins.
Vigara Tauste, Ana María (1992): Morfosintaxis del español coloquial, Madrid, Gredos.

White, Peter R.R. (2003): «Beyond modality and hedging: A dialogic view of the language of intersubjective stance», Text, 23 (2), 259-284.

Yus, Francisco (2011): Cyberpragmatics. InternetMediated Communication in Context, Amsterdam/Philadelphia, John Benjamins.

Yus, Francisco (2017): «Los efectos de Internet y las redes sociales en el español», Boletín de la Academia Puertorriqueña de la lengua española, 2017, 55-76. 